\title{
College Student Sleep Quality Following Sleep Classes
}

\author{
Kathy Sexton-Radek \\ Suburban Pulmonary \& Sleep Associates, Elmhurst University, Elmhurst, USA \\ Email: ksrsleep@aol.com
}

How to cite this paper: Sexton-Radek, K. (2020) College Student Sleep Quality Following Sleep Classes. Health, 12, 1409-1414. https://doi.org/10.4236/health.2020.1210102

Received: August 25, 2020

Accepted: October 27, 2020

Published: October 30, 2020

Copyright $\odot 2020$ by author(s) and Scientific Research Publishing Inc. This work is licensed under the Creative Commons Attribution International License (CC BY 4.0).

http://creativecommons.org/licenses/by/4.0/

\begin{abstract}
Sleep hygiene and knowledge about sleep basics is unknown in college student populations. The college student population have abbreviated sleep due to social schedules and busy academic schedules. A measurement of sleep hygiene and knowledge about sleep in the college student population indicates that there are varying levels along with sleep knowledge. The objective of the study was to examine young adult sleep quality because of providing an educative intervention. A sleep class of one hour provided once a week for ten weeks was provided following the administration of a ten-item sleep survey. Following the sleep class, the sleep survey was read ministered. Measures of central tendency and non-parametric analysis of nominal data were conducted. The results indicated two of the five cohorts had statistically significant differences. Further, the measures of sleep quality differed, statistically, for two of the cohorts receiving the classroom instruction. This research finding indicates a continued need to educate college student populations about their sleep health.
\end{abstract}

\section{Keywords}

Sleep Quality, Sleep, Sleep Deprivation

\section{Background}

Sleep hygiene is a widely practiced intervention for poor sleep quality. Since the inception of Sleep Hygiene by Dr. Peter Hauri of the Mayo Clinic, these behavioral steps have been considered to address poor sleep quality [1]. Sleep hygiene refers to a collection of behavior alterations for the purpose of improving sleep [2] [3]. Restraints from alcohol, nicotine, exercise, late night meals, excessive caffeine intake and bright lights of technology have been identified to heighten arousal and therefore be incompatible with sleep quality [4] [5] [6] [7]. Addi- 
tionally, having a regular wakeup time to signal wakefulness to the brain in the sleep wake cycle is considered of great importance setting one's sleep/wake cycle. This group of practices promotes higher quality and longer duration of sleep [3] [6] [8]. Periodicals, advice from medical visits and various media distributions of information about sleep include "sleep hygiene." Metanalytical studies of behavioral interventions to improve sleep have identified sleep hygiene as not significant—despite its grand popularity [3] [9].

\section{Introduction}

Young adult sleep has been identified as compromised secondary to their choices of giving up sleep for activities [4] [10] [11]. The underestimation of the value of sleep health is problematic in many age groups with the young adults and teenagers seemingly putting the lowest regard on sleep health [12]. Seven to eight hours of sleep are recommended for young adult sleep with reports indicating an average of six hours [13] [14]. Contemporary society, for the college student, is translated to their academic schedule, a work schedule and their self-initiated social activities which typically involve large amounts of technology use (i.e. tablet/smartphone use with social media). College student schedules are often filled with class time, laboratory time, and work [3] [15] [16]. Following this, choice about homework time and social activities are made. In the recent five years, technology usage has grown and is estimated to now encompass some $32 \%$ of young adults' day (e.g. checking Facebook, texts, emails) [9] [17]. It may be that these behaviors are active as they require cognitive activity (i.e. attention, concentration). Decreased sleep quality is associated with lower grade point averages and performance on vigilance (cognitive) tasks. Additionally, more accidents occur among population of sleep deprived young adults (college students). The findings of poor sleep are also associated with increased infections secondary to reduction in immune system functioning [3]. Some 55\% of TVAs involve young adults with a substantial proportion being college students [3]. This circumstance is intensified by the measurement of college students' perceptions when they are sleep deprived, the college student typically has distorted, overestimated views of their performances when sleep deprived. Substance use is common in the college student population and often results in sleep disturbance [3]. Evaluation in this area reports that substance use is linked to "Sleeping," "getting to sleep" by college students [6]. College students ranked sleep difficulty as third behind stress and anxiety on self-report scales [1] [17] [18] [19] [20] [21] [22].

In summary, college student sleep has been measured to be compromised in terms of severe reduction in sleep schedules that increase the risk of poor sleep in young adults [3] [19] [20] [21] [22] [23]. Responsibilities and personal choices with free-unstructured time are emotionally and physically budgeted in their schedule each day. The recognition of sleep health and potential benefit of sleep health to their functioning is not valued [3] [4] [6] [10] [12] [22]. A prevailing 
assumption, per college student self-report is that they know about sleep health but do not apply their learning.

\section{Study Aim}

The current evaluation measured cohorts of college students' knowledge about sleep and then presented them with classroom instruction about the basics of sleep followed by a self-report measure about their sleep to test this hypothesis.

\section{Method}

\subsection{Participants}

The study sample included 86 participants with an average age of 25 years keep track of their sleep using a sleep log. All participants attended ten one-hour weekly sessions of instructions about sleep. Students enrolled in a seminar class at a small midwestern college were invited to participate in the study in exchange for course credit and a summary of the study findings. Participants ranged in ages 19 to 23 years old with a mean age of 21 years. Overall, there were $62 \%$ females in each cohort class. The participants came from a population from Midwest Small University Introductory Psychology course where course credit could be earned as points toward 5\% of their grade with participation. Participants were excluded from the study if they had a sleep disorder and/psychiatric diagnosis. Participants were included in the study if they selected the study from groupings of studies available to them to earn course credit.

\subsection{Instruments}

A ten-item sleep survey where the participant responded "true for me" or "false for me" to each statement was presented as a pretest followed by ten weeks of one-hour class meetings focused on topics of sleep hygiene, general sleep, dreaming, circadian rhythm. The sleep survey was re-administered following the ten class meetings.

\section{Results}

To test the relationship between the participants knowledge about sleep, a Chisquare analysis of the pre and post instruction was conducted. The sleep survey before and after ten weeks of one hour classroom instruction about sleep, circadian rhythm, sleepiness by cohort resulted in statistically significant difference from pre to post testing for cohorts 1 and 4. Wilcoxen test across all cohorts by pretest and posttest of sleep survey total score was not significant. Paired t-test analysis of pre and post rating of sleep quality were statistically significant for cohorts 1 and 4. To examine the participants' application of the sleep knowledge, their sleep by data in terms of their ratings from pre to post ten weeks of classroom instruction was conducted. The results of the analyses are presented in $\mathrm{Ta}$ ble 1 and Table 2. 
Table 1. Chi square results for pre and post testing scores of sleep knowledge by cohort $(\mathrm{n}=86)$.

\begin{tabular}{ccc}
\hline Cohort \# & Cohort Size & Chi Square \\
\hline 1 & 17 & $0.29^{*}$ \\
2 & 15 & 0.11 \\
3 & 17 & 0.07 \\
4 & 18 & $0.35^{*}$ \\
5 & 19 & 0.23 \\
\hline
\end{tabular}

Note: ${ }^{\star}=0.05$ probability.

Table 2 . Results of pre to post sleep quality ratings ${ }^{\star}$.

\begin{tabular}{cc}
\hline Cohort & t-test (paired) \\
\hline 1 & 0.07 \\
2 & $0.27^{*}$ \\
3 & 0.23 \\
4 & 0.09 \\
5 & $0.19^{*}$ \\
\hline
\end{tabular}

Note: Standard sleep log daily rating of sleep quality composed of 1 - 5 Rating Scale where 1 = poor sleep last night, $2=$ somewhat poor sleep, $3=$ neutral rating poor nor good sleep, $4=$ somewhat good sleep last night, $5=$ good sleep last night. ${ }^{*}=0.05$ significance level.

Eighty-six participants with an average age of 25 years keep track of their sleep using a sleep log. All participants attended ten one-hour weekly sessions of instructions about sleep.

\section{Conclusions and Implications}

Participants learned in small, regular meetings for them to improve their sleep hygiene and facilitate the application of sleep knowledge. Interventions such as this classroom format are useful to increase the awareness of sleep problems in society for students. Evaluations of this 10-week intervention may be explored further with different modalities-online, 1:1. In addition, Public Health promotion of sleep health such as the recent World Sleep day 3/17/2020, was useful in conveying information about sleep health globally.

The sleep hygiene and knowledge about their sleep pattern provided the participants, through the classroom instruction with accurate information about their sleep quality and specific steps to try to improve their sleep quality. The structured directive nature of the classroom experience provided a social milieu of exchanging information at the individual level which also contributed to improved motivation to make changes to improve sleep as classroom "peer pressure" or perhaps "friendly competition" leading the participants to consider trying the strategies suggested in class. Taken together, the provision of information and individualized guidance is presupposed to account for the changes in sleep hygiene. These principles are not unlike professional information dissemi- 
nation of the Public Health professional.

\section{Recommendations}

1) Healthy Sleep instruction is essential to the college student population; the implementation of a classroom format is effective in increasing college students' sleep quality [3] [4] [6] [22].

2) The transference of learning about sleep health to heightened awareness of one's sleep quality and attempts to improve sleep can be accomplished through a classroom format [3] [4] [6] [22].

\section{Conflicts of Interest}

The author declares no conflicts of interest regarding the publication of this paper.

\section{References}

[1] Naitoh, P., Kelly, T.L. and Englund, C. (1990) Health Effects of Sleep Deprivation. Occupational Medicine: Sates of the Art Reviews, 5, 209-237.

[2] Blunden, S.L., Chapman, J. and Rigney, G.A. (2012) Are Sleep Education Programs Successful? The Case for Improved and Consistent Research Efforts. Sleep Medicine Reviews, 16, 355-370. https://doi.org/10.1016/j.smrv.2011.08.002

[3] Sexton-Radek, K. (2003) Sleep Quality in Young Adults. Edward Mellon Press, New York.

[4] Sexton-Radek, K. (2019) Screen Time Effects. Open Access Journal of Neuroscience and Neurosurgery, 11, 77-78.

[5] Wells, M.E. and Vaugh, B.V. (2012) Poor Sleep Challenging the Health of a Nation. Neurodiagnostic Journal, 52, 233-249.

[6] Valerio, T.D., Kim, M.J. and Sexton-Radek, K. (2016) Association of Stress, General Health, and Alcohol Use among U.S. College Students Related to Poor Sleep Quality. American Journal of Health Education, 47, 17-23. https://doi.org/10.1080/19325037.2015.1111173

[7] Thomée, S., Härenstam, A. and Hagberg, M. (2011) Mobile Phone Use and Stress, Sleep Disturbance and Symptoms of Depression among Young Adults-A Prospective Cohort Study. BMC Public Health, 11, Article No. 66. https://doi.org/10.1186/1471-2458-11-66

[8] Lack, P. and Rotert, M. (1986) Knowledge and Practice of Sleep Hygiene Techniques in Insomniacs and Good Sleepers. Behavior Research and Therapy, 24, 365-368. https://doi.org/10.1016/0005-7967(86)90197-x

[9] Sexton-Radek, K. and Hartley, A. (2013) College Residential Sleep Environment. Psychological Reports. Mental \& Physical Health, 113, 903-907. https://doi.org/10.2466/06.10.PR0.113x27z2

[10] Cheng, S.H., Shih, C.C., Lee, I.H., Hou, Y.W., Chen, K.C., Chen, K.T., Yang, Y.K. and Yang, Y.C. (2012) A Study on the Sleep Quality of Incoming University Students. Psychiatry Research, 197, 270-274. https://doi.org/10.1016/j.psychres.2011.08.011

[11] Forquer, L.M., Camden, A.E., Gabriau, K.M. and Johnson, C.M. (2008) Sleep Patterns of College Students at a Public University. Journal of American College Health, 
56, 563-565. https://doi.org/10.3200/JACH.56.5.563-565

[12] Hicks, R.A., Lucero-Gorman, K., Bautista, J. and Hickes, G.J. (1999) Ethnicity, Sleep Hygiene Knowledge, and Sleep Hygiene Practices. Perceptual and Motor Skills, 88, 1095-1096. https://doi.org/10.2466/pms.1999.88.3c.1095

[13] Crowley, S.J. and Carskadon, M.A. (2010) Modification to Weekend Recovery Sleep Delay Circadian Phase in Older Adolescents. Journal Chronobiology International, 27, 1469-1492. https://doi.org/10.3109/07420528.2010.503293

[14] Ahrberg, K., Dresler, M., Nidermaier, S., Steiger, A. and Genzel, L. (2012) The Interaction between Sleep Quality and Academic Performance. Journal of Psychiatric Research, 46, 1618-1622. https://doi.org/10.1016/j.jpsychires.2012.09.008

[15] Onyper, S.V., Thacher, P.V., Gilbert, J.W. and Gradess, S.G. (2012) Class Start Times, Sleep, and Academic Performance in College: A Path Analysis. Chronobiology International, 29, 318-335. https://doi.org/10.3109/07420528.2012.655868

[16] Scott, J.P.R., McNaughton, L.R. and Polman, R.C.J. (2006) Effects of Sleep Deprivation and Exercise on Cognitive, Motor Performance and Mood. Physiology \& Behavior, 87, 396-408. https://doi.org/10.1016/j.physbeh.2005.11.009

[17] Pilcher, J.J. and Walters, A.S. (1997) How Sleep Deprivation Affects Psychological Variables Related to College Students' Cognitive Performance. Journal of American College Health, 46, 121-126. https://doi.org/10.1080/07448489709595597

[18] Mastin, D.F., Bryson, J. and Corwyn, R. (2006) Assessment of Sleep Hygiene Using the Sleep Hygiene Index. Journal of Behavioral Medicine, 29, 223-227. https://doi.org/10.1007/s10865-006-9047-6

[19] Lim, J. and Dinges, D.F. (2010) A Meta-Analysis of the Impact of Short-Term Sleep Deprivation on Cognitive Variables. Psychological Bulletin, 136, 375-389. https://doi.org/10.1037/a0018883

[20] Wolfson, A.R. and Carskadon, M.A. (1998) Sleep Schedules and Daytime Functioning in Adolescents. Child Development, 69, 875-887. https://doi.org/10.1111/j.1467-8624.1998.tb06149.x

[21] Zee, P.C. and Turek, F.W. (2006) Sleep and Health: Everywhere and in Both Directions. Archives of Internal Medicine, 166, 1686-1688.

https://doi.org/10.1001/archinte.166.16.1686

[22] Hershner, S. and Chervin, R. (2014) Causes and Consequences of Sleepiness among College Students. Nature and Science of Sleep, 6, 73-84. https://doi.org/10.2147/NSS.S62907

[23] Lund, H.G., Reider, B.D., Whiting, A.B. and Prichards, J.R. (2010) Sleep Patterns and Predictors of Disturbed Sleep in a Large Population of College Students. Journal of Adolescent Health, 46, 124-132.

https://doi.org/10.1016/j.jadohealth.2009.06.016 